\title{
COCONUT SHELL-BASED ACTIVATED CARBON AS ADSORBENT FOR THE REMOVAL OF DYE FROM AQUEOUS SOLUTION: EQUILIBRIUM, KINETICS, AND THERMODYNAMIC STUDIES
}

\author{
O. Oribayo ${ }^{1,}{ }^{*}$, O. O. Olaleye ${ }^{2}$, A. S. Akinyanju ${ }^{3}$, K.O. Omoloja ${ }^{4}$ and S.O. Williams ${ }^{5}$

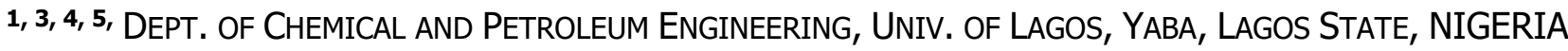 \\ 2, DEPARTMENT OF PHARMACEUTICAL CHEMISTRY, UNIVERSITY OF LAGOS, YABA, LAGOS STATE, NIGERIA \\ E-mail addresses: 1 ooribayo@unilag.edu.ng, 2 ffnancyolaleye@gmail.com, \\ 3aakinyanju@unilag.edu.ng, ${ }^{4}$ kenyhalen@yahoo.com, 5 samuelwilliams022@gmail.com
}

\begin{abstract}
The need to develop more efficient adsorbent, comparable to commercially available adsorbent, is attracting significant interest as promising adsorbent for waste water treatment. In this study, the potential of activated carbon prepared from waste coconut shell (CSAC) for the removal of methylene blue (Mb) from aqueous solution was reported. Batch experiments were conducted to determine the adsorption isotherm and kinetics of Mb on CSAC. Langmuir, Freundlich and Temkin isotherm models were employed to fit and analyze the adsorption equilibrium data. The result shows Langmuir isotherm model gave the best fit and an adsorption capacity of 320.5 $\mathrm{mg} / \mathrm{g}$ was obtained for $\mathrm{Mb}$ at $\mathrm{pH}$ value of $7,0.02 \mathrm{~g}$ adsorbent dosage and contact time of 4.5 hour. The experimental kinetic data at different initial Mb concentrations was also analyzed with pseudo-first order, pseudo-second order and intraparticle diffusion models. The obtained results showed that the pseudo-second order model fits the adsorption kinetic data with $\boldsymbol{R}^{2}$ range of 0.9985-0.9996. Finally, the thermodynamic parameters show that the adsorption of Mb on CSAC was spontaneous and endothermic in nature. This therefore suggests that (CSAC) is a viable adsorbent for effective removal of dye from wastewater effluent.
\end{abstract}

Keywords: Activated carbon, Adsorption isotherms, Coconut shells, Methylene blue, kinetics.

\section{INTRODUCTION}

Dye effluent discharge into the environment from textile, plastic, paper and leather industries is a source of water pollution which is harmful to aquatic life and has deleterious effects on human health $[1$, 2]. For instance, acute exposure to dye such as methylene blue, a commonly used pigment for dyeing wool, leather, cotton and as temporary hair colorant has negative and harmful effect on humans if swallowed or inhaled. It causes irritation in the gastrointestinal tract if swallowed with symptoms such as nausea, vomiting, diarrhea, and increase in human heart rate [3-5]. If inhaled, it can result to convulsions, cyanosis and jaundice [6]. Therefore, the treatment of wastewater effluent prior to its final discharge to the environment, to remove dye and pigment is of great environmental importance. To address this challenge, various methods such as electrochemical treatment, microbial degradation, membrane separation, adsorption and biological techniques have been employed to remove pollutant from industrial wastewater effluent. Among this method, the use of adsorption is particularly promising and attractive because the technique is efficient and economical in terms of costeffectiveness and process simplicity.

The cost effectiveness of preparing activated carbon from agricultural waste and the possibility of tailoring its structure and properties makes it desirable for adsorption process. They could possess tunable functionality, large specific surface area, and welldefined porosity. Generally, it is visible to prepare

* Corresponding author, Tel: +234-806-546-0626 
activated carbon via physical or chemical activation or a combination of both. It has been the most popular adsorbent in removal of pigments and in wastewater treatment owing to its inherent abilities to adsorb pollutants. However, commercially available activated carbons are relatively expensive due to complicated production processes and expensive precursors, which could make them less attractive for use as an adsorbent [7].

In recent years, studies have focused on a growing research interest for preparing activated carbons from cheaper precursors such as agricultural waste by-products. El-sayed et al. [8] prepared three different activated carbons from corncob via chemical activation with phosphoric acid. The prepared adsorbent was used to remove methylene blue from aqueous solution and the kinetic and equilibrium data from the batch adsorption studies, were employed to understand the adsorption process. Theydan et al. [9] investigated the utilization of ferric chloride as an activator for the preparation of activated carbon from an agricultural date pit. Equilibrium adsorption data of methylene blue onto the prepared ferric chloride activated carbon was reported to be well described by Sips isotherm model, with $R^{2}$ value of 0.9995 . Pseudo second order model describe the adsorption kinetic data and the obtained thermodynamic data indicated the spontaneous and endothermic nature of methylene blue adsorption on the adsorbent. Their conclusions suggest that the adsorbent may find practical applications for removal of dye pollutants form industrial water effluent.

Alam et al. [10] investigated the possibility of utilizating rice husk activated carbon as an adsorbent for the removal of methylene blue dye from aqueous solutions. The effects of various experimental parameters, like initial dye concentration, $\mathrm{pH}$, adsorbent dosage and adsorbent particle size were investigated. The methylene blue maximum uptake from the aqueous solution by the activated rice husk carbon at optimized conditions was $97.15 \%$. Their results indicate that activated carbon from agricultural rice husk waste has favourable surface properties and could be employed as low-cost alternatives to commercial activated carbon in the removal of basic dyes in waste water treatment.

In this study, coconut shell based activated carbon was prepared via chemical activation, using waste coconut shell precursor from agricultural waste due to its abundance. Its abundant supply as a waste- product from the coconut oil and desiccated coconut industry, may make producing activated carbon from this material financially viable. Also, it is an amorphous form of carbon with high density, high purity and dust free nature advantage. Herein, coconut shell-based activated carbon was prepared via chemical activation with $\mathrm{ZnCl}_{2}$ for the removal of methylene blue dye from aqueous solution. The equilibrium, kinetics and thermodynamics data on batch adsorption studies of methylene blue dye onto the prepared coconut shell-based activated carbon (CSAC) adsorbent were carried out, to understand its adsorption process and determine the spontaneity, endothermic or exothermic nature of the process. The properties and performance of the coconut shell based activated carbon in relation to adsorption were also investigated.

\section{MATERIALS AND METHODS}

\subsection{Materials}

Activated carbon used in this study was prepared from waste coconut shells. The impurities in the waste coconut shells were removed via washing with distilled water and subsequently dried at $60^{\circ} \mathrm{C}$ for 5 h. The obtained coconut shell was then crushed using electric pulverize and sieved with mesh sieve. All the chemicals used were of analytical grade, purchased from Shanghai Chemical Reagents Co. Ltd. China and used as received. These include Zinc chloride (99.9\%), hydrochloric acid (99.9\%) and Methylene blue (Mb) (99.9\%). Distilled water form laboratory water distiller was used in this study.

\subsection{Preparation of activated carbon}

The sieved coconut shell precursor was carbonized in a muffle furnace (BST/MF/1800, Bionics Scientific, Delhi) at a temperature of $600^{\circ} \mathrm{C}$ for $3 \mathrm{~h}$ and allowed to cool. The carbonized coconut shell $(150 \mathrm{~g})$ was soaked in a $150 \mathrm{ml}$ of $\mathrm{ZnCl}_{2}$ solution for $8 \mathrm{~h}$ at activation weight ratio of $1: 1 \mathrm{~g}$ activator to precursor. The impregnated samples, coconut shell activated carbon (CSAC) was then washed with distilled water several times to obtain activated carbon of almost neutral pH (6.5-7.0) and subsequently dried in an electric oven (MINO/100, Genlab, UK), at $80^{\circ} \mathrm{C}$ for $2 \mathrm{~h}$. Finally, the sample was stored in a tightly closed container. The activated carbon yield, which is defined as the ratio of final weight of the product obtained after washing and drying to the weight of the initially dried precursor used was determined by, 


$$
\text { Yield }(\%)=\frac{\mathrm{W}_{\mathrm{f}}}{\mathrm{W}_{\mathrm{o}}} \times 100
$$

where $\mathrm{W}_{\mathrm{f}}$ and $\mathrm{W}_{\mathrm{o}}$ are the weight of final activated carbon product $(\mathrm{g})$ and the weight of dried coconut shells precursor $(g)$, respectively.

\subsection{Characterizations}

The surface morphology of the pristine coconut shell carbon (CSC) and the coconut shell activated carbon (CSAC) was studied using a scanning electron microscopy (Quanta 200 FEG, FEI Company, USA). The adsorbent was sputtered with gold before observation under SEM.

\subsection{Adsorption isotherms}

The equilibrium isotherm of $\mathrm{Mb}$ adsorption on CSAC, adsorption tests were carried out using $100 \mathrm{ml}$ conical flasks in which $50 \mathrm{ml}$ of Mb solutions with different initial concentrations $(50-450 \mathrm{mg} / \mathrm{l})$ was placed in each flask. The solutions $\mathrm{pH}$ was adjusted to $\mathrm{pH}$ of 7 by adding $0.1 \mathrm{M} \mathrm{HCl}$ solution gradually. Activated carbon $(0.02 \mathrm{~g})$ was added to each flask and placed in a shaker at $115 \mathrm{rpm}, 303 \mathrm{~K}$ for $4.5 \mathrm{~h}$ to attain equilibrium. The samples were filtered and the concentrations of the residue of $\mathrm{Mb}$ in the filtrate were analyzed by a UV-Visible Spectrophotometer. UV-Vis spectrophotometer (LAMBDA 750, PERKIN ELMER $^{\circledR}$ ) was employed to analyze the residue concentration of the $\mathrm{Mb}$ in the filtrate at $664 \mathrm{~nm}$ wave length. The adsorbed amount of $\mathrm{Mb}$ at equilibrium, $\mathrm{q}_{\mathrm{e}}(\mathrm{mg} / \mathrm{g})$ was calculated by the expression,

$$
\mathrm{q}_{\mathrm{e}}=\frac{\left(\mathrm{C}_{\mathrm{o}}-\mathrm{C}_{\mathrm{e}}\right) \mathrm{V}}{\mathrm{w}}
$$

where $\mathrm{C}_{\mathrm{o}}$ and $\mathrm{C}_{\mathrm{e}}(\mathrm{mg} / \mathrm{L})$ are the initial and equilibrium concentrations of $\mathrm{MB}$ solution, respectively, $\mathrm{W}(\mathrm{g})$ is the weight of activated carbon used and $\mathrm{V}$ is the volume of the solution in liter. Langmuir $[11,12]$, Freundlich [11, 12], and Temkin $[12,13]$ isotherm models were used to fit the experimental isotherm data of $\mathrm{Mb}$ adsorption onto CSAC. The isotherms are as follows:

Langmuir isotherm,

$$
\mathrm{q}_{\mathrm{e}}=\frac{\mathrm{q}_{\mathrm{L}} \mathrm{K}_{\mathrm{L}} \mathrm{C}_{\mathrm{e}}}{1+\mathrm{K}_{\mathrm{L}} \mathrm{C}_{\mathrm{e}}}
$$

Freundlich isotherm,

$$
\mathrm{q}_{\mathrm{e}}=\mathrm{K}_{\mathrm{F}} \mathrm{C}_{\mathrm{e}}^{1 / \mathrm{n}}
$$

Temkin isotherm,

$$
q_{e}=\frac{R T}{b} \ln \left(K_{T} C_{e}\right)
$$

Linearize form of Temkin isotherm is expressed as, where

$$
q_{e}=\beta \ln K_{T}+\beta \ln C_{e}
$$

$$
\beta=\frac{\mathrm{RT}}{\mathrm{b}}
$$

The essential equilibrium parameter for the Langmuir isotherm $(R \mathrm{~L})$, can be expressed as,

$$
\mathrm{R}_{\mathrm{L}}=\frac{1}{\mathrm{k}_{\mathrm{L}}+\mathrm{C}_{\mathrm{o}}}
$$

Where $\mathrm{k}_{\mathrm{L}}(\mathrm{L} / \mathrm{mg})$ is the Langmuir constant related to rate of adsorption, $\mathrm{q}_{\mathrm{L}}(\mathrm{mg} / \mathrm{g})$ is the Langmuir maximum uptake of $\mathrm{Mb}$ per unit mass of CSAC, $n$ is Freundlich constant which indicate adsorption intensity, $K_{F}\left((\mathrm{mg} / \mathrm{g})(\mathrm{L} / \mathrm{mg})^{1 / \mathrm{n}}\right)$ is Freundlich constants which gives a measure of adsorption capacity. $\mathrm{T}$ is the absolute temperature in Kelvin, $\mathrm{R}$ is the universal gas constant $(8.314 \mathrm{~J} / \mathrm{mol} \mathrm{K})$, and $\mathrm{b}$ is the Temkin constant related to heat of sorption (J/mg). The Temkin constants $K_{T}$ and b are calculated from the slope and intercept of $q_{e}$ versus $\log C_{e} . \mathrm{C}_{\mathrm{o}}$ is the highest initial solute concentration, and $R_{L}$ indicates the type of isotherm [reversible ( $R_{L}$ $=0)$, favorable $\left(0<R_{L}<1\right)$, linear $\left(R_{L}=1\right)$ or unfavorable $\left(R_{L}>1\right)$ ]. From the plots, the parameters from the equations can be used to establish the accord between experimental observation and theory in terms of the $\mathrm{R}^{2}$ correlation coefficient value.

\subsection{Adsorption kinetics}

The procedure used for adsorption equilibrium experiments was repeated here at different time intervals (0.25-5.5 h). A temperature of $303 \mathrm{~K}$ and a $\mathrm{pH}$ of 7 was maintained for the various solutions. The absorbent $(0.02 \mathrm{~g})$ was put into each conical flask containing $\mathrm{Mb}$ solutions and the flasks were shaken at $110 \mathrm{rpm}$. At the end of each of the contact time, the samples were filtered and the residual concentrations in the filtrate were analyzed by a UVVisible Spectrophotometer. The amount of $\mathrm{Mb}$ adsorbed at time $\mathrm{t}, \mathrm{q}_{\mathrm{t}}(\mathrm{mg} / \mathrm{g})$, was calculated by:

$$
\mathrm{q}_{\mathrm{t}}=\frac{\left(\mathrm{C}_{\mathrm{o}}-\mathrm{C}_{\mathrm{t}}\right) \mathrm{V}}{\mathrm{w}}
$$

where $C_{t}(\mathrm{mg} / \mathrm{L})$ is the liquid-phase concentration of $\mathrm{Mb}$ solution at time $\mathrm{t}$ ( $\mathrm{min})$. Three models namely; Pseudo-first order model, pseudo-second order model, and intraparticle diffusion model were used to analyze the kinetic data. These models are:

Pseudo-first order model,

$$
\ln \left(q_{t}-q_{e}\right)=\ln \left(q_{e}\right)-k_{1} t
$$

Pseudo-second order model, 
Coconut Shell-Based Activated Carbon as Adsorbent for the Removal of Dye from Aqueous,.... O. Oribayo, et al.

$$
\frac{\mathrm{t}}{q_{t}}=\frac{1}{\mathrm{~K}_{2} \mathrm{q}_{\mathrm{e}}}+\frac{\mathrm{t}}{\mathrm{q}_{\mathrm{e}}}
$$

Intraparticle diffusion model,

$$
q_{t}=K_{3} t^{\frac{1}{2}}+\mathrm{C}
$$

where $\mathrm{q}_{\mathrm{e}}$ is and $q_{t}(\mathrm{mg} / \mathrm{g})$ are the uptake of $\mathrm{Mb}$ at equilibrium and at time $\mathrm{t}(\mathrm{min})$, respectively. $\mathrm{K}_{1}$ $\left(\mathrm{min}^{-1}\right)$ is the adsorption rate constant, $\mathrm{K}_{2}$ ( $\mathrm{g} / \mathrm{mg}$.min) is the rate constant of second-order equation, $K_{3}\left(\mathrm{mg} / \mathrm{g} \mathrm{min}^{1 / 2}\right)$ is the intraparticle diffusion rate constant, and $\mathrm{C}(\mathrm{mg} / \mathrm{g})$ is a constant that shows the boundary layer thickness. $\Delta \mathrm{q}(\%)$ is the normalized standard deviation which validates the applicability of the kinetic models in describing the adsorption process value, defined as:

$$
\Delta \mathrm{q}(\%)=100 \sqrt{\frac{\sum\left(\mathrm{q}_{\text {exp }}-\mathrm{q}_{\mathrm{cal}} / \mathrm{q}_{\mathrm{exp}}\right)^{2}}{\mathrm{~N}-1}}
$$

where $\mathrm{N}$ is the number of data points, $\mathrm{q}_{\mathrm{cal}}$ and $\mathrm{q}_{\exp }$ $(\mathrm{mg} / \mathrm{g})$ are the calculated and experimental adsorption capacities, respectively.

\subsection{Adsorption thermodynamics}

The effect of temperature to the adsorption capacity of the adsorbent was carried out at 30,40 and $50^{\circ} \mathrm{C}$ in a constant water bath using $\mathrm{pH} \mathrm{7,115} \mathrm{rpm} \mathrm{and}$ $0.02 \mathrm{~g}$ of adsorbent for $4.5 \mathrm{~h}$ to achieve equilibrium. At the end of $4.5 \mathrm{~h}$, the samples were filtered and the residual concentrations of methylene blue in the filtrate was analyzed by a UV-Visible Spectrophotometer. The adsorbed amount of $\mathrm{Mb}$ at equilibrium, $q_{e}(\mathrm{mg} / \mathrm{g})$ was calculated and the thermodynamic behavior of $\mathrm{Mb}$ adsorption onto CSAC was evaluated using thermodynamic parameters, which include the change in free energy $(\Delta \mathrm{G})$, enthalpy $(\Delta \mathrm{H})$, and entropy $(\Delta \mathrm{S})$. These parameters were derived using the following equations [9]:

$$
\begin{gathered}
K_{d}=\frac{q_{e}\left(\frac{\mathrm{W}}{\mathrm{V}}\right)}{C_{e}} \\
\Delta G=-R T \ln \left(K_{d}\right) \\
\ln \left(K_{d}\right)=\frac{\Delta \mathrm{S}}{\mathrm{R}}-\frac{\Delta \mathrm{H}}{\mathrm{RT}}
\end{gathered}
$$

where $\mathrm{R}$ is the universal gas constant (8.314 ( $\mathrm{J} / \mathrm{mole}) \mathrm{K}), \mathrm{T}$ is temperature $(\mathrm{K})$, and $K_{d}$ is the distribution coefficient for the adsorption.

\section{RESULTS AND DISCUSSION}

\subsection{Yield and characteristics}

Figure 1 shows the Scanning Electron Microscope images for the coconut shells and prepared activated carbon. As shown in Figure 1a, the surface of unactivated coconut shells is very smooth compared to Figure $1 \mathrm{~b}$ with rougher surface. After $\mathrm{ZnCl}_{2}$ impregnation and activation at $600{ }^{\circ} \mathrm{C}$ activation temperature, it was observed that the homogeneity between the un-activated coconut shell carbon and its matrix decreases in comparison to coconut shell activated carbon (CSAC). The surface of CSAC became rougher and its surface topology differed as shown in Figure $1 \mathrm{~b}$.

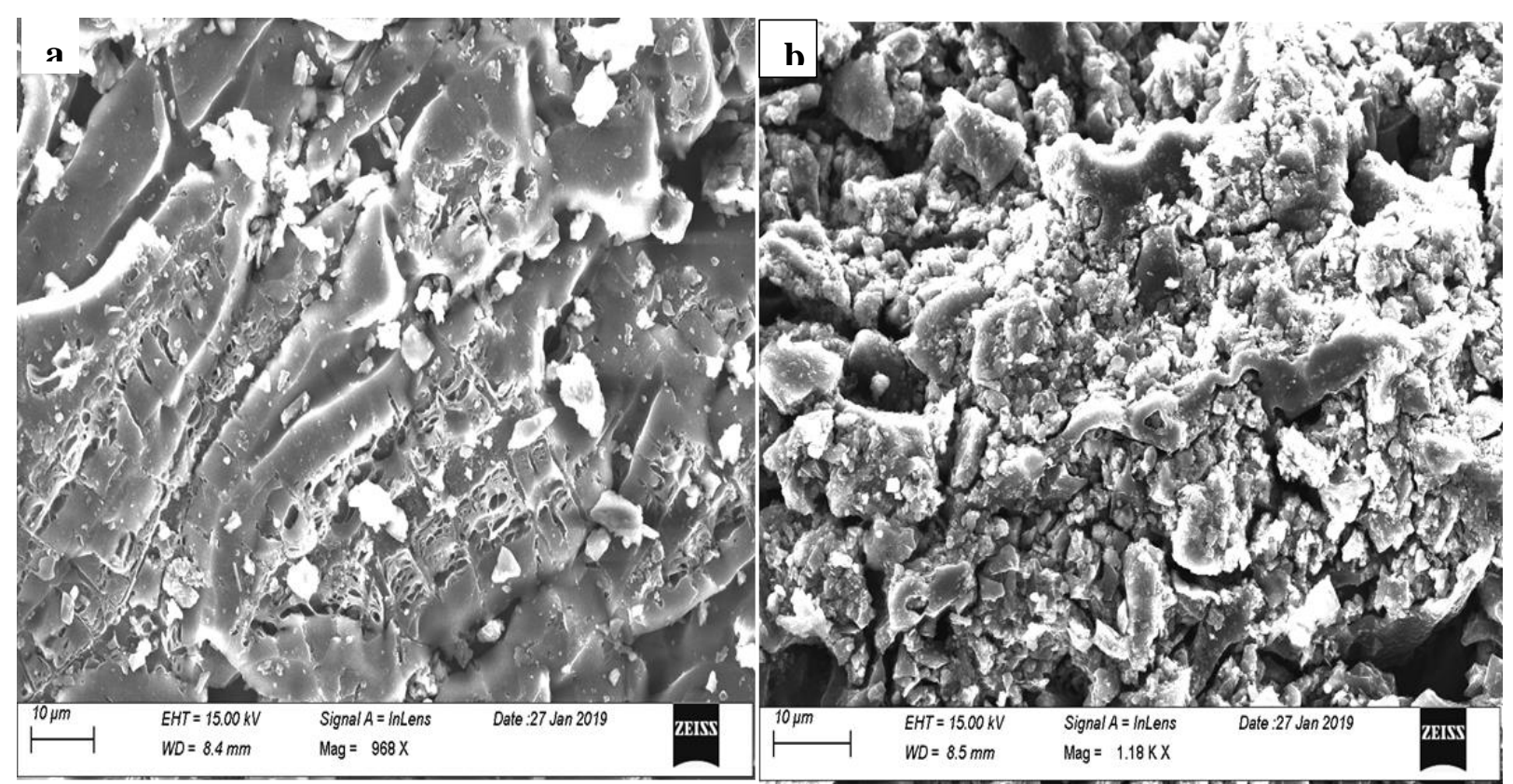

Figure 1: Surface morphologies of pristine coconut shell carbon (CSC) (1a) and coconut shell activated carbon (CSAC) (1b) 


\subsection{Adsorption isotherm}

The equilibrium experimental data for $\mathrm{Mb}$ adsorption on CSAC were fitted with Langmuir, Freundlich and Temkin isotherms, using equations (3), (4) and (5). These three isotherm equations constants along with the $R^{2}$ values are calculated as shown in Table 1 and the correlated adsorption isotherm are shown in Figures $2 b, 3 a$ and $3 b$. From Table 1 , the correlation coefficient, $R^{2}$ values for the Langmuir, Freundlich and Temkin isotherms at $303 \mathrm{~K}$ are 0.9923 , and $0.8888,0.9591$ respectively. According to the linear regression method, the Freundlich and Temkin isotherms were poorly suitabile to the adsorption of the activated carbon prepared from CSAC in comparison to the Langmuir isotherm which gave the best correlation. This can also be observed in Figure $2 \mathrm{a}$, where the Langmuir isotherm was the best fit to the experimental isotherm and this reflects monolayer adsorption. The validity of the Langmuir model indicated that the dye uptake was due to monolayer coverage of solute particles onto the surface of the activated carbon and adsorption of each molecule had equal activation energy. The same behavior was observed by Hameed et al., [14], Peydayesh and Rahbar-Kelishami [15].

From Table 1, it can be seen that the Langmuir isotherm, values of $R_{L}$ is 0.139 for adsorption of $\mathrm{Mb}$. This indicated that the adsorption behavior of activated carbon was favourable for the dye $\left(R_{L}<1\right)$. Also, a maximum Mb adsorption capacity of 324.78 $\mathrm{mg} / \mathrm{g}$ was obtained from the Langmuir isotherm fitting and compared to those obtained in the literature from various agricultural wastes as seen in Table 2. As shown in Table 2, the adsorption capacity of CSAC adsorbent used in this study for the removal of methylene blue in aqueous solution, is comparable to those previously reported in literature. CSAC shows much higher maximum adsorption capacity than some reported adsorbent, such as platanus orientalis leaves powder, walnut shell-carbon, oil palm shell-carbon, cotton stalk carbon, ficus carica bast carbon, rice husk carbon, citrus fruit peelcarbon and Apricot stones-carbon Furthermore, CSAC adsorption capacity is low when compared with d65ate stones-carbon. However, CSAC adsorbent used in this study is agricultural waste-based at almost cost free, relative to Date stones-carbon adsorbent. This comparison, indicates that CSAC is an efficient and low-cost adsorbent than some existing adsorbent for methylene blue sorption. Therefore, CSAC can be classified as one of the effective adsorbents for wastewater treatment and could be utilized instead of the conventional adsorbent.

\subsection{Adsorption kinetics}

Figure $4 a$ shows the effect of CSAC adsorption capacity on $\mathrm{Mb}$, using different initial concentrations. This figure depicts an increase in the adsorption capacity of $\mathrm{Mb}$ with an increase in contact time. It also indicates that the adsorption reached equilibrium in about $4.5 \mathrm{~h}$. The amount of $\mathrm{Mb}$ adsorbed at various time interval was obtained using Equation 9 and correlated with the pseudo-first order, pseudo-second order and intraparticle diffusion models, Equations $10-12$. The constants and $R^{2}$ values for these models at different initial concentration of $\mathrm{Mb}$ are tabulated in Table 3. It can be observed that $\mathrm{R}^{2}$ value of pseudo-first order and interparticle diffusion models are of low values compared to pseudo-second order model. This indicates the measure of pseudo-second order model fits the kinetic experimental data. Furthermore, a large difference was observed between the calculated and experimental values of adsorption capacity $(\Delta q(\%))$, which also confirm the fit of pseudo-second order model in contrast to pseudofirst order model. The pseudo-second order linear plot of $t / q_{t}$ against $t$ which depict the high $R^{2}$ value of good fit as shown in Figure 5a. It is therefore evident that the adsorption kinetics of Mb on CSAC is better represented by second-order kinetics.

Table 1: Adsorption isotherm plot parameters for Mb on CSAC

\begin{tabular}{llllll}
\hline Models & \multicolumn{3}{c}{ Isotherm Constant } & & \\
\hline Langmuir & Temp $(\mathrm{K})$ & $q_{L}(\mathrm{mg} / \mathrm{g})$ & $\mathrm{K}_{\mathrm{L}}(\mathrm{l} / \mathrm{mg})$ & $\mathrm{R}_{\mathrm{L}}$ & $\mathrm{R}^{2}$ \\
& 303 & 324.780 & 0.014 & 0.139 & 0.992 \\
Freundlich & Temp $(\mathrm{K})$ & $1 / \mathrm{n}$ & $\mathrm{K}_{\mathrm{F}}(\mathrm{mg} / \mathrm{g})(l / \mathrm{mg})^{1 / \mathrm{n}}$ & $\mathrm{N}$ & $\mathrm{R}^{2}$ \\
& 303 & 0.4631 & 25.950 & 2.159 & 0.889 \\
\multirow{2}{*}{ Temkin } & Temp $(\mathrm{K})$ & $\beta$ & $K_{T}(\mathrm{l} / \mathrm{mg})$ & $\mathrm{B}$ & $\mathrm{R}^{2}$ \\
& 303 & 189.430 & 0.190 & 13.300 & 0.959 \\
\hline
\end{tabular}



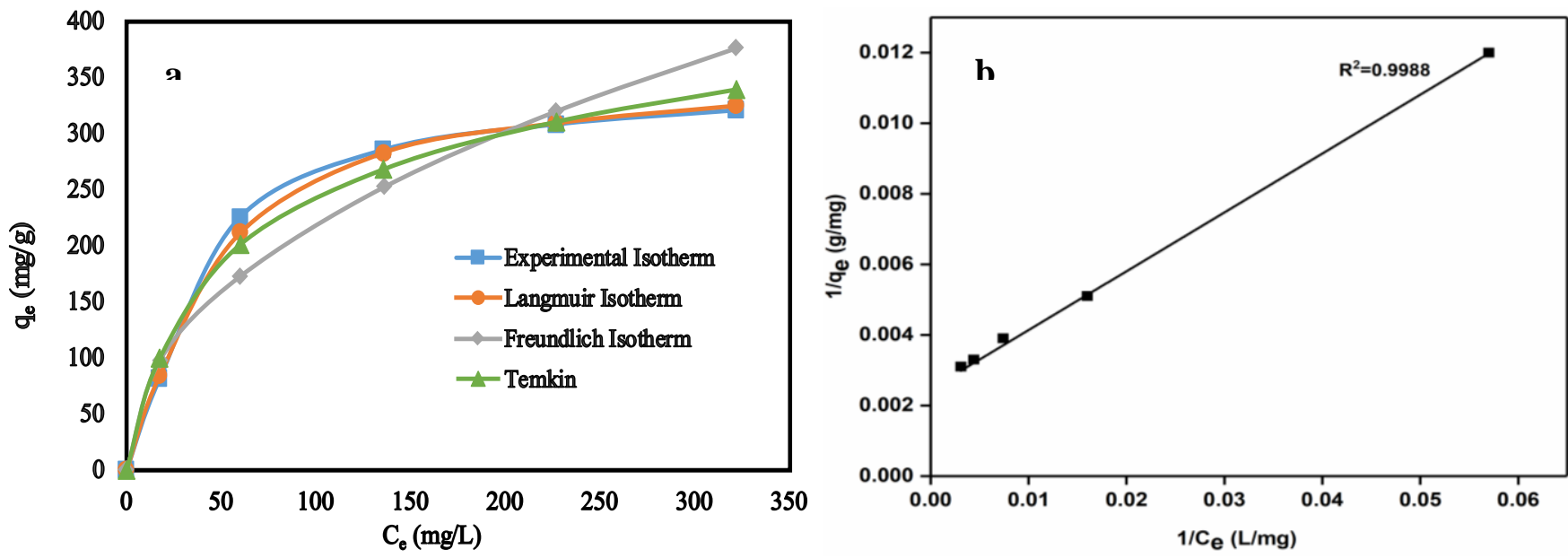

Figure 2: (a) Isotherm models comparison for Mb adsorption on CSAC (b) Langmuir isotherm for Mb adsorption on CSAC. [ contact time (4.5hr), pH (7), adsorbent dosage (0.02g)]
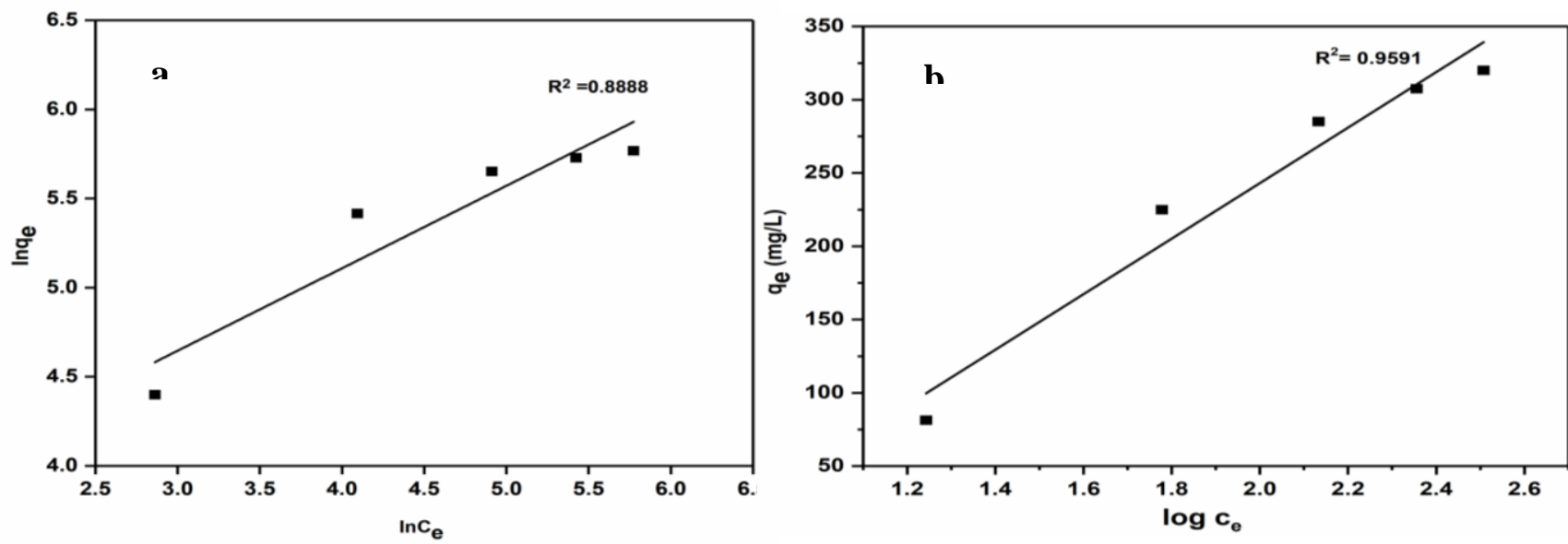

Figure 3: (a) Freundlich, (b)Temkin adsorption isotherm of Mb adsorption unto CASC. [Contact time (4.5hr), $\mathrm{pH}(7)$, adsorbent dosage $(0.02 \mathrm{~g})]$

Table 2: Comparison of Methylene blue (Mb) adsorption capacity onto activated carbons (each adsorbate is methylene blue)

\begin{tabular}{lcc}
\hline Adsorbent & Maximum capacity $(\mathrm{mg} / \mathrm{g})$ & Reference \\
\hline Coconut shell-carbon & 320.50 & This study \\
Platanus orientalis leaves powder & 114.94 & {$[15]$} \\
Date stones-carbon & 398.19 & {$[9]$} \\
Walnut shell-carbon & 315.00 & {$[16]$} \\
Oil palm shell-carbon & 277.78 & {$[17]$} \\
Cotton stalk carbon & 193.5 & {$[18]$} \\
Ficus carica bast carbon & 48.5 & {$[19]$} \\
Rice Husk carbon & 47 & {$[10]$} \\
Citrus fruit peel-carbon & 20 & {$[20]$} \\
Apricot stones-carbon & 4.11 & {$[21]$} \\
\hline
\end{tabular}

Intraparticle diffusion model, Equation 12 is widely used to predict the rate controlling step. The values of $\mathrm{R}^{2}$ for this model is lower in comparison with values obtained from the pseudo- second and pseudo-first order models. A high deviation between the calculated and experimental values $\Delta \mathrm{q}(\%)$ was also observed (Table 3 ). In concluding that the intraparticle diffusion is the rate controlling step, the plot of $q_{t}$ versus $t^{1 / 2}$ should be linear and pass through the origin. As shown in Figure 5b, the plot 
did not go through the origin. From these results, it can be concluded that intraparticle diffusion is not the dominating mechanism for the adsorption of $\mathrm{Mb}$ from aqueous solution by prepared activated carbon. Accordingly, the optimum adsorption factors obtained were shaking speed of $110 \mathrm{rpm}$, adsorbent dosage of $0.02 \mathrm{~g}$, initial concentration of $450 \mathrm{mg} / \mathrm{L}$, and contact time of 4.5 hours for $92.39 \%$ removal of methylene blue.

\subsection{Adsorption thermodynamics}

Applying equation 14, the values of the distribution coefficient for adsorption $\left(K_{d}\right)$ at different temperature were obtained from the adsorption isotherm data. The values of $\Delta \mathrm{G}, \Delta \mathrm{H}$, and $\Delta \mathrm{S}$ for $\mathrm{MB}$ were then obtained using equation 15 and 16. $\Delta \mathrm{H}$ and $\Delta \mathrm{S}$ were obtained from the slope and intercept of the plot of $\ln K_{d}$ against $1 / T$ (Figure 6 ), and the calculated values are tabulated in Table 4 . The obtained values for Gibbs free energy change $(\Delta G)$ for the adsorption of Mb on CASC are -1559.35 , -1956.70 , and $-2107.78 \mathrm{~J} / \mathrm{mole}$ at the temperature of $303 \mathrm{~K}, 313 \mathrm{k}$, and $323 \mathrm{~K}$ respectively. The negative value of the Gibbs free energy is an indication of the thermodynamically spontaneous nature of the $\mathrm{Mb}$ adsorption on CSAC. A decrease in the feasibility of adsorption was observed at higher temperatures as indicated by the decrease in $\Delta G$ values with increasing temperature.

Table 3: Kinetic Parameters for Adsorption of methylene blue (Mb) on CSAC

\begin{tabular}{|c|c|c|c|c|c|c|}
\hline \multirow{7}{*}{$\begin{array}{l}\text { PSEUDO-FIRST } \\
\text { ORDER MODEL }\end{array}$} & $\mathrm{Co}(\mathrm{mg} / \mathrm{L})$ & $\mathrm{q}_{\mathrm{e}, \exp }$ & $\mathrm{q}_{\mathrm{e}, \mathrm{cal}}$ & $\mathrm{K}_{1}(1 / \mathrm{min})$ & $\mathrm{R}^{2}$ & $\Delta \mathbf{q}(\%)$ \\
\hline & 50 & 81.25 & 38.11 & 0.0121 & 0.9516 & 26.55 \\
\hline & 150 & 225 & 59.84 & 0.0123 & 0.9365 & 36.70 \\
\hline & 250 & 285 & 63.91 & 0.0169 & 0.9827 & 38.79 \\
\hline & 350 & 307.5 & 86.10 & 0.0113 & 0.9798 & 36.00 \\
\hline & 450 & 320 & 103.77 & 0.0113 & 0.9531 & 33.79 \\
\hline & $\mathrm{Co}(\mathrm{mg} / \mathrm{L})$ & $\mathrm{q}_{\mathrm{e}, \exp }$ & $\mathrm{q}_{\mathrm{e}, \mathrm{cal}}$ & $\mathrm{K}_{2}(\mathrm{~g} / \mathrm{mgmin})$ & $\mathrm{R}^{2}$ & $\Delta \mathrm{q}(\%)$ \\
\hline \multirow{6}{*}{$\begin{array}{l}\text { PSEUDO-SECOND } \\
\text { ORDER MODEL }\end{array}$} & 50 & 81.25 & 85.47 & 3.34 & 0.9989 & 2.597 \\
\hline & 150 & 225 & 232.56 & 7.17 & 0.9994 & 1.680 \\
\hline & 250 & 285 & 294.12 & 11.33 & 0.9996 & 1.600 \\
\hline & 350 & 307.5 & 312.5 & 8.00 & 0.9996 & 0.813 \\
\hline & 450 & 320 & 333.33 & 5.00 & 0.9985 & 2.083 \\
\hline & $\mathrm{Co}(\mathrm{mg} / \mathrm{L})$ & $\mathrm{q}_{\mathrm{e}, \exp }$ & $\mathrm{C}(\mathrm{mg} / \mathrm{g})$ & $\mathrm{K}_{3}\left(\mathrm{mg} / \mathrm{gmin}^{1 / 2}\right)$ & $\mathrm{R}^{2}$ & \\
\hline \multirow{5}{*}{$\begin{array}{l}\text { INTRAPARTICLE } \\
\text { DIFFUSION MODEL }\end{array}$} & 50 & 81.25 & 39.298 & 20.194 & 0.8542 & \\
\hline & 150 & 225 & 157.510 & 32.752 & 0.8103 & \\
\hline & 250 & 285 & 224.430 & 29.948 & 0.7980 & \\
\hline & 350 & 307.5 & 218.320 & 41.969 & 0.9238 & \\
\hline & 450 & 320 & 215.530 & 48.683 & 0.9420 & \\
\hline
\end{tabular}
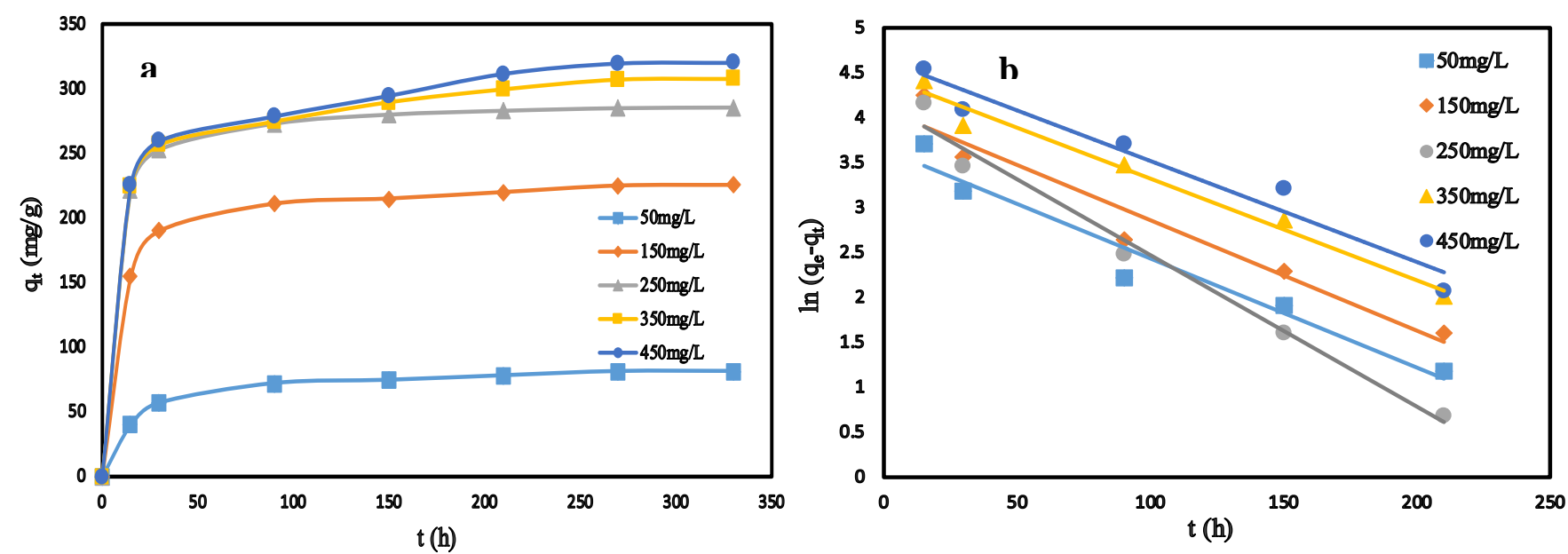

Figure 4: (a) Contact time effect on Mb adsorbed on CSAC at different initial concentration. (b) Pseudo-first order kinetic for Mb adsorption on CSAC at different initial concentration. [ $\mathrm{pH}(7)$, temperature $303 \mathrm{~K}$, adsorbent dosage (0.02)]. 

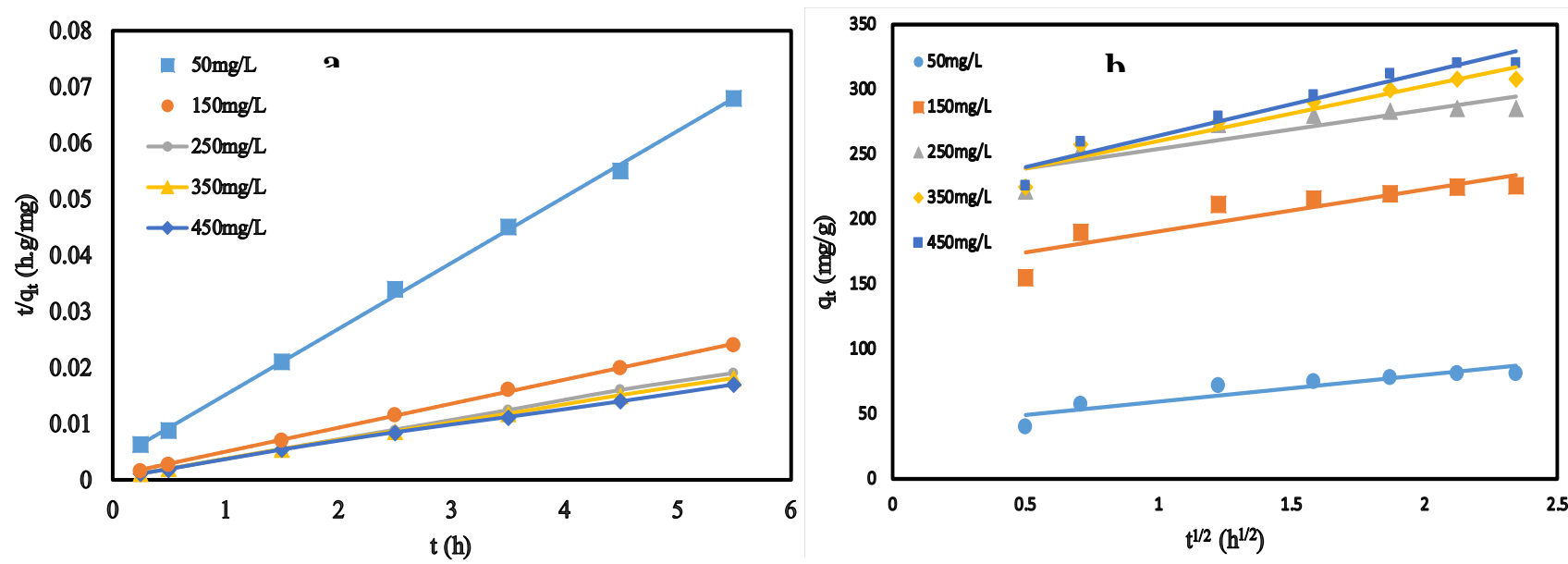

Figure 5: (a) Pseudo-second order kinetic for Mb adsorption on CSAC at different concentration, (b) Intraparticle diffusion model for Mb adsorption on CSAC at different initial concentration [temperature (303 $\mathrm{K}), \mathrm{pH}(\mathrm{7})$, adsorbent dosage $(0.02 \mathrm{~g})]$.

Table 4: Thermodynamics adsorption parameters for Mb on CSAC.

\begin{tabular}{lllll}
\hline$\Delta \mathrm{H}(\mathrm{J} / \mathrm{mole})$ & $\Delta \mathrm{S}(\mathrm{J} /($ mole $)(\mathrm{K}))$ & \multicolumn{3}{c}{$-\Delta \mathrm{G}(\mathrm{J} / \mathrm{mole})$} \\
\hline \multirow{2}{*}{7015.76} & \multirow{2}{*}{26.15} & $303 \mathrm{~K}$ & $313 \mathrm{~K}$ & $323 \mathrm{~K}$ \\
\cline { 3 - 5 } & & 1559.35 & 1956.70 & 2107.78 \\
\hline
\end{tabular}

The $\Delta \mathrm{H}$ value is $7015.76 \mathrm{~J} /$ mole for $\mathrm{Mb}$ adsorption on CSAC and this positive value indicate the endothermic nature of the adsorption. Adsorption enthalpy ranging from 2.1 to $20.9 \mathrm{~kJ} / \mathrm{mol}$ correspond to physical adsorption and this indicate that the adsorption of $\mathrm{Mb}$ on CASC is physisorption $[9,22]$. Also, the positive value of $\Delta S(26.15$ $\mathrm{J} / \mathrm{mole}$ ) indicates that during the adsorption process there is an increase in the randomness at adsorbate-solution interface which enhance the process.

\section{CONCLUSIONS}

In conclusion, the preparation of activated carbon from waste coconut shell with zinc chloride activation and its ability to remove methylene blue (Mb) from aqueous solutions was reported in this study. The maximum adsorption capacity of $\mathrm{Mb}$ on CASC was $320.5 \mathrm{mg} / \mathrm{g}$ at a $\mathrm{pH}$ value of $7,0.02 \mathrm{~g}$ adsorbent dose and $4.5 \mathrm{~h}$ contact time. Langmuir isotherm fits the equilibrium adsorption data for $\mathrm{Mb}$ adsorption with a correlation coefficient $\left(R^{2}\right)$ value of 0.9923 . The pseudo-second order model describes the adsorption kinetics data. The calculated thermodynamic parameters namely $\Delta G$, $\Delta \mathrm{H}$ and $\Delta \mathrm{S}$ indicates the spontaneous and endothermic nature of $\mathrm{Mb}$ adsorption onto CSAC under the examined conditions. This study indicates its potential as effective adsorbent for removal of dye from wastewater effluent.

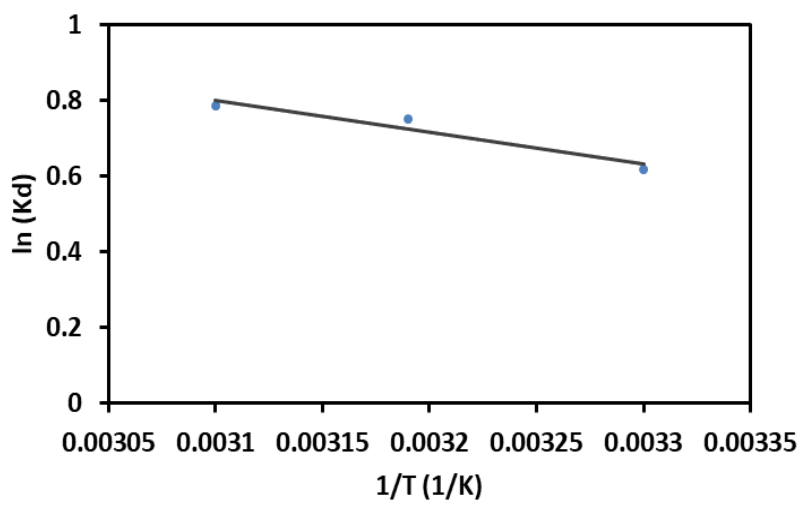

Figure 6: Plot of In (Kd) versus $1 / T$ for $M b$ adsorption on CSAC (Co $=50 \mathrm{mg} / \mathrm{L}$, time $=4.5 \mathrm{~h}$, $\mathrm{pH}=7$, adsorbate dosage $=0.02 \mathrm{~g}$ ).

\section{REFERENCES}

[1] Zhou, Y., Ge, L., Fan, N. and Xia, M. Adsorption of Congo red from aqueous solution onto shrimp shell powder, Adsorption Science \& Technology, vol.36, pp.1310-1330, 2018.

[2] Bulut, E., Ozacar, M. and Sengil, I. A. Equilibrium and kinetic data and process design for adsorption of Congo Red onto bentonite, $J$ Hazard Mater, vol.154, pp.613-622, 2018.

[3] Berradi, M., Hsissou, R., Khudhair, M., Assouag, M., Cherkaoui, O., El-Bachiri, A. and El-Harfi, A. Textile finishing dyes and their impact on aquatic environs, Heliyon, 5(02711), 2019. 
[4] Lellis, B., Fávaro-Polonio, C. Z., Pamphile, J.A. and Polonio, J. C. Effects of textile dyes on health and the environment and bioremediation potential of living organisms, Biotechnology Research and Innovation. Vol.3, pp. 275-290, 2019.

[5] Luo, L., Wu, X., Li, Z., Zhou, Y., Chen, T., Fan, $M$. and Zhao, W. Synthesis of activated carbon from biowaste of fir bark for methylene blue removal, $R$ Soc Open Sci. vol. 6, pp.190523, 2019.

[6] Vutskits, L., Briner, A., Klauser, P., Gascon, E., Dayer, A.G., Kiss, J. Z., Muller, D., Licker, M.J. and Morel, D.R. Adverse Effects of Methylene Blue on the Central Nervous System, Anesthesiology, vol.208, pp.684-692, 2008.

[7] Elamin, A., Reddy, M.R. and Rehrah, D. Activated Carbon from Almond Shells to Adsorb the Heavy Metals from Contaminated Water, International Journal of Chemistry Environment and Technology. Vol.1, pp.1-8, 2013.

[8] El-Sayed, G. O., Yehia, M. M. and Asaad, A. A. Assessment of activated carbon prepared from corncob by chemical activation with phosphoric acid, Water Resources and Industry. vol.7-8, pp.66-75, 2014.

[9] Theydan, S. K. and Ahmed, M. J. Adsorption of methylene blue onto biomass-based activated carbon by $\mathrm{FeCl} 3$ activation: Equilibrium, kinetics, and thermodynamic studies, Journal of Analytical and Applied Pyrolysis. Vol.97, pp.116-122, 2012.

[10] Alam, A. M. S., Amin, S. M. R. and Rahman, M. A. Removal of Methylene Blue from Waste Water Using Activated Carbon Prepared from Rice Husk, Dhaka University Journal of Science. vol.60, pp.185-189, 2012.

[11] Garba, Z.N., Bello, I., Galadima, A. and Lawal, A.Y. Optimization of adsorption conditions using central composite design for the removal of copper (II) and lead (II) by defatted papaya seed, Karbala International Journal of Modern Science. Vol.2, pp.20-28, 2016.

[12] Dada, A. O., Olalekan, A. P. and Olatunya, A. M. Langmuir, Freundlich, Temkin and Dubinin-Radushkevich Isotherms Studies of Equilibrium Sorption of Zn2+ Unto Phosphoric Acid Modified Rice Husk, IOSR Journal of Applied Chemistry, vol.3, pp.38-45, 2012.

[13] Ayawei, N., Ebelegi, A.N., Wankasi, D. Modelling and Interpretation of Adsorption Isotherms, Journal of Chemistry, pp. 1-11, 2017.
[14] Hameed, B. H., Mahmoud, D. K. and Ahmad, A. L. Equilibrium modeling and kinetic studies on the adsorption of basic dye by a low-cost adsorbent: coconut (Cocos nucifera) bunch waste, J Hazard Mater. Vol.158, pp.65-72, 2008.

[15] Peydayesh, M. and Rahbar-Kelishami, A. Adsorption of methylene blue onto Platanus orientalis leaf powder: Kinetic, equilibrium and thermodynamic studies, Journal of Industrial and Engineering Chemistry, vol. 21, pp.1014-1019, 2015.

[16] Yang, J. and Qiu, K. Preparation of activated carbons from walnut shells via vacuum chemical activation and their application for methylene blue removal, Chemical Engineering Journal, vol.165, pp.209-217, 2010.

[17] Tan, I. A, W., Hameed, B. H. and Ahmad, A.L. Equilibrium and kinetic studies on basic dye adsorption by oil palm fibre activated carbon, Chemical Engineering Journal, vol.127, pp. 111-119, 2007.

[18] Deng, H., Yang, L., Tao, G. and Dai, J. Preparation and characterization of activated carbon from cotton stalk by microwave assisted chemical activation--application in methylene blue adsorption from aqueous solution, J Hazard Mater, vol.166, pp.1514$1521,2009$.

[19] Pathania, D., Sharma, S. and Singh, P. Removal of methylene blue by adsorption onto activated carbon developed from Ficus carica bast, Arabian Journal of Chemistry, vol.10, pp. S1445-S1451, 2017.

[20] Dutta, S., Bhattacharyya, A., Ganguly, A., Gupta, S. and Basu, S. Application of Response Surface Methodology for preparation of low-cost adsorbent from citrus fruit peel and for removal of Methylene Blue, Desalination, vol.275, pp.26-36, 2011.

[21] Aygün, A., Yenisoy-Karakaş, S. and Duman, I. Production of granular activated carbon from fruit stones and nutshells and evaluation of their physical, chemical and adsorption properties, Microporous and Mesoporous Materials, vol. 66, pp.189-195, 2003.

[22] Aljeboree, A. M., Alkaim, A. F. and Al-Dujaili, A. $\mathrm{H}$. Adsorption isotherm, kinetic modeling and thermodynamics of crystal violet dye on coconut husk-based activated carbon, Desalination and Water Treatment, vol. 53, pp. 3656-3667, 2014. 